\title{
Influence of Community-Based Dental Education on Dental Students' Preparation and Intent to Treat Underserved Populations
}

\author{
Wilhelm A. Piskorowski, D.D.S.; Stephen J. Stefanac, D.D.S., M.S.; \\ Mark Fitzgerald, D.D.S., M.S.; Thomas G. Green, Ph.D.; Rachel E. Krell, B.A.
}

Abstract: This study examined the influence of community-based dental education (CBDE) on dental students' perceived ability to treat underserved patients and their selection of community dental clinics as a first career path. In a 2009 survey, fourth-year dental students at the University of Michigan recorded their attitudes, skill level, and confidence in treating underserved patients before and after CBDE rotations and estimated what percentage of their practice they planned to devote to Medicaid-eligible patients. The first career choices of graduates from 2005 to 2010 were also correlated with the number of weeks the students spent in CBDE rotations. The results showed an improvement in student skill and confidence in treating low-income patients after the rotations. The examination of first career choices showed that, after three to five weeks of CBDE rotations, 5.6 percent of the students planned to practice in a community-based dental clinic. However, in 2009 when rotations were increased to eight weeks and included multiple clinic types, 11.8 percent of the students in 2009 and 16.5 percent in 2010 selected a community-based dental clinic as their preferred practice location. These findings suggest that CBDE improves dental students' skill and confidence level in treating underserved patients and that more time spent in CBDE rotations, specifically more than five weeks in multiple clinic types, may increase the number of graduates who select practice in community-based clinics as a first career choice.

Dr. Piskorowski is Director for Outreach and Community Affairs, School of Dentistry, University of Michigan; Dr. Stefanac is Associate Dean for Patient Services, School of Dentistry, University of Michigan; Dr. Fitzgerald is Associate Professor and Associate Chair, Department of Cariology, Restorative Sciences, and Endodontics, School of Dentistry, University of Michigan; Dr. Green is Lecturer, Department of Periodontics and Oral Medicine, School of Dentistry, University of Michigan; and Ms. Krell is a first-year dental student, School of Dentistry, University of Michigan. Direct correspondence and requests for reprints to Dr. Wilhelm Piskorowski, School of Dentistry, University of Michigan, 1011 North University Ave., Ann Arbor, MI 48109-1078; 734-764-7389 phone; 734-615-6338 fax; wapdds@umich.edu.

Keywords: access to care, dental education, underserved populations, community-based dental education, community dentistry, oral health care for the underserved

Submitted for publication 5/23/11; accepted 9/19/11

$\mathrm{P}$ roviding dental care to underserved populations has become an increasing challenge in many regions of the United States. One strategy for increasing the dental workforce practicing in safety net clinics has been to enhance student awareness of opportunities to serve low-income and underserved patients by participation in communitybased dental education (CBDE).

Evaluative research on students' community rotations has led to significant findings on the immediate value of service-learning to a dental school, its students, and the surrounding community. Student rotations in community-based clinics can increase net revenues to their dental school, ${ }^{1}$ attract more ethnically diverse students to the dental profession, ${ }^{2}$ and improve productivity in community-based clinics. ${ }^{3}$ Students on community-based rotations develop an increased awareness of health care disparities, ${ }^{4} \mathrm{dem}$ onstrate improved self-confidence in their clinical abilities, ${ }^{5,6}$ and benefit from exposure to a more di- verse patient pool. ${ }^{7}$ These studies have been effective in demonstrating the importance of service-learning to dental education; however, research on student intentions to treat low-income and underserved populations after graduation has found conflicting results.

Several studies have focused on the personal characteristics, values, and backgrounds of individual students to understand which are more likely to choose practice settings that serve high numbers of low-income and underserved patients. ${ }^{8-12}$ These investigations have suggested that characteristics such as race and ethnicity, attitudes, and beliefs influence the likelihood that a student will treat underserved populations. However, these studies do not address how CBDE programs influence student practice choices after graduation.

The American Dental Education Association (ADEA) survey of dental seniors has been used to study the influence of CBDE on students planning to work in community-based dental clinics. Two 
studies that used data from this survey found that the number of weeks students spent in CBDE rotations was a significant determinant of their intentions and ability to provide care to patients from diverse backgrounds. ${ }^{8,13}$ In contrast, another study based on data from the survey using a multivariate analysis found that the students' practice plans to work in community settings were unchanged by the duration of CBDE rotations. ${ }^{14}$ This annual ADEA survey is an important resource for information on a national scale; however, it offers little insight into which aspects of a CBDE program have the greatest influence on student preparation and desire to care for underserved populations.

A couple of programs have evaluated the influence of community-based education on dental students' intent to treat low-income and underserved patients, but have shown conflicting results. A study by Smith et al. ${ }^{15}$ at the University of Michigan School of Dentistry found a positive relationship between a curriculum that focused on treating underserved patients and student and alumni intentions to treat patients from diverse backgrounds. A study by DeCastro et al. ${ }^{16}$ of the New Jersey Dental School community-based program found no difference in intentions to treat low-income and underserved patients between alumni who had participated in the program and those who treated patients at the dental school. Overall, the conflicting results of these studies suggest a need for more schools to evaluate the effect of their CBDE programs on student practice decisions.

The objectives of this study were therefore as follows: 1) to compare one group of dental students' perceived attitudes, skill level, and confidence in treating low-income and underserved patients before and after their CBDE rotations; and 2) to examine the first career choices of graduating dental students based on the number of weeks they spent in CBDE rotations.

\section{Methods}

In 2009, a randomly chosen half of the fourthyear dental class (fifty-eight students) completed a survey regarding their CBDE rotations at the end of their final semester at the University of Michigan School of Dentistry. Students were asked to report their attitudes, perception of skill level, and confidence in treating underserved patients before and after their rotations and estimate what percentage of their future practice would include Medicaid-eligible patients. This survey was a part of the end of the semester assessments that students are required to complete for courses and instructors; its use was approved by the University of Michigan Institutional Review Board. The Pearson chi-square test was performed on all comparative questions.

All students surveyed participated in at least eight weeks of CBDE rotations during their fourth year in the state of Michigan at Federally Qualified Health Centers (FQHCs), Indian Health Service clinics, and/or a private practice clinic that serves low-income patients. Some students also provided treatment to migrant farm workers and to low-income patients in developing countries. At all locations, students treated patients who were at or below 200 percent of the U.S. poverty level.

To examine the effect of CBDE rotations on students' first career paths, the first career choices of graduating dental students were examined based on the number of weeks they spent in CBDE rotations. Immediately prior to graduation, the students reported where they would be working to the dental school registrar. These reports were examined from 2005 and 2010, and the number of students planning to work in community-based clinics was compared to those who chose a different path. The registrar's records prior to 2005 are no longer available, but the percentage of students who chose community-based settings before the CBDE program was established (1998-2000) was calculated in a previous study of the University of Michigan School of Dentistry's program. ${ }^{17}$

\section{Results}

After fifty-eight students (100 percent response rate) responded to the 2009 survey, we compared their attitudes toward treating underserved patients before and after their CBDE rotations (Table 1). The result of the Pearson chi-square test $(p=0.440)$ indicated no significant change in students' attitude after their externships. However, the attitude of most students (around 80 percent) remained favorable or very favorable toward treating underserved patients both before and after the rotations.

We also compared the students' perception of their skill level in treating low-income and underserved patients before and after the CBDE rotations (Table 2). About half (47.4 percent) ranked their skill level as average before the rotations, but only 19.3 percent ranked their skill level as average after the 
rotations - a decrease of 28.1 percent. The percentage of students who reported an above average skill level increased by 15.7 percent after the rotations. The percentage of students who reported their skill level in treating the underserved as excellent also increased by 12.3 percent after the rotations. Overall, the students' perception of their skill level significantly increased after their CBDE rotations (Pearson chi-square test, $\mathrm{p}=0.005$ ).

In comparisons of the students' confidence level in treating underserved patients before and after their outreach rotations (Table 3), almost half (48.2 percent) rated their confidence level as average or low before the rotations. After the rotations, no student reported having a low confidence level, and 17.5 percent ranked their confidence as average - an improvement of 30.7 percent. The percentage of students who rated their confidence level as high increased by 14.8 percent after the rotations, and the students who rated their confidence as very high increased by 16 percent after the rotations. These increases in student confidence level were also statistically significant (Pearson chi-square test, $\mathrm{p}=0.002$ ).

In that survey, students were asked what percentage of their practice they expected would include Medicaid-eligible patients (Table 4). Around one-third planned to devote less than 10 percent of their practice to Medicaid-eligible patients. About one-third planned to devote 10 to 25 percent of their practice to these patients, and the remaining one-third planned to devote more than 25 percent of their practice to these patients.

The first career choice of graduating students from 2005 to 2010 was compared to the number of weeks they spent in community rotations (Table 5). From 1998 to 2000, before the existence of the CBDE program, only 1.7 percent of the students chose a community-based clinic as their first career choice. From 2005 to 2007, students completed three to four weeks of outreach in FQHC clinics, and each

Table 1. Comparison of students' attitudes toward treating underserved patients before and after community rotations in 2009

\begin{tabular}{lccc} 
Survey Response & Before Rotation & After Rotation & Change \\
\hline Very favorable & $32.8 \%$ & $44.8 \%$ & $+12 \%$ \\
Favorable & $50.0 \%$ & $36.2 \%$ & $-13.8 \%$ \\
Neutral & $15.5 \%$ & $15.5 \%$ & 0 \\
Unfavorable & $1.7 \%$ & $3.4 \%$ & $+1.7 \%$ \\
Pearson chi-square test: $\mathrm{p}=0.440$ & &
\end{tabular}

Table 2. Comparison of students' perception of their skill level in treating underserved patients before and after community rotations in 2009

\begin{tabular}{lccc} 
Survey Response & Before Rotation & After Rotation & Change \\
\hline Excellent & $12.3 \%$ & $24.6 \%$ & $+12.3 \%$ \\
Above average & $40.4 \%$ & $56.1 \%$ & $+15.7 \%$ \\
Average & $47.4 \%$ & $19.3 \%$ & $-28.1 \%$ \\
Pearson chi-square test: $\mathrm{p}=0.005$ & &
\end{tabular}

Table 3. Comparison of students' confidence level in treating underserved patients before and after community rotations in 2009

\begin{tabular}{lccc} 
Survey Response & Before Rotation & After Rotation & Change \\
\hline Very high & $8.6 \%$ & $24.6 \%$ & $+16 \%$ \\
High & $43.1 \%$ & $57.9 \%$ & $+14.8 \%$ \\
Average & $44.8 \%$ & $17.5 \%$ & $-27.3 \%$ \\
Low & $3.4 \%$ & 0 & $-3.4 \%$
\end{tabular}

Pearson chi-square test: $p=0.002$ 
of those years six students chose a community-based clinic as their first career choice, for an average of 5.6 percent of graduating students. In 2008, students spent five weeks in FQHC clinics, and seven students (5.6 percent of the class) chose community-based clinics as their first career choice.

A significant increase in students' selection of community dental clinics as their first career path was observed in 2009 and 2010 when the time they spent in CBDE rotations increased to eight weeks and included multiple types of community clinics. At all outreach locations, students treated patients that were at or below 200 percent of the poverty level. In 2009, students completed outreach rotations in FQHCs, Indian Health Service clinics, a private practice clinic that serves low-income patients, and multiple international sites. The 2009 data show thirteen students (11.8 percent) chose a community-based clinic as their first career choice. In 2010, students also completed eight weeks of rotations, though in even more clinic types including FQHCs, Indian Health Service clinics, a private practice, community health centers, a correctional facility, international locations, and fully donated care clinics. That year, eighteen students (16.5 percent of the class) chose a community-based clinic as their first career choice.

\section{Discussion}

We believe that community-based education experiences make important contributions to a student's professional growth. This study demonstrates how CBDE improves students' confidence and perceived skill level when treating low-income and un-
Table 4. Expectation of students to include Medicaideligible patients in their future practice

\begin{tabular}{lcc}
$\begin{array}{l}\text { Percentage } \\
\text { of Future Practice }\end{array}$ & $\begin{array}{c}\text { Number } \\
\text { of Students }\end{array}$ & $\begin{array}{c}\text { Percentage } \\
\text { of Students }\end{array}$ \\
\hline$<10 \%$ & 18 & $31 \%$ \\
$10-25 \%$ & 18 & $31 \%$ \\
$26-50 \%$ & 9 & $15 \%$ \\
$51-75 \%$ & 8 & $14 \%$ \\
$>75 \%$ & 5 & $9 \%$
\end{tabular}

derserved patients. Our data also suggest that several weeks spent in CBDE rotations that offer experiences in a variety of community dental health care settings can increase the likelihood that a student will select a community dental clinic as a first career choice.

The student survey in 2009 showed a significant increase in perceived student skill and confidence level when treating low-income and underserved patients after CBDE rotations and that students' attitudes were positive both before and after the rotations. After spending eight weeks in CBDE rotations, the students felt more prepared to treat low-income and underserved patients after graduation than before these rotations. The survey also revealed that, after the CBDE rotations in 2009, a large portion of the graduates planned to include low-income, Medicaid-eligible patients as part of their future dental practice. Two-thirds of the survey respondents planned to devote at least 10 percent of their future practice to Medicaid-eligible patients. Furthermore, 23 percent of those who planned to devote at least 10 percent of their future practice to Medicaid-eligible patients intended to treat these

Table 5. Community-based clinics as students' first career choice compared to the number of weeks spent in community rotations in 1998-2000 and from 2005 to 2010, by number of students and percentage of total graduates in that class

First Career Choice

\begin{tabular}{lcccccc}
\cline { 3 - 6 } & $\begin{array}{c}\text { Weeks Spent } \\
\text { in Rotations }\end{array}$ & $\begin{array}{c}\text { Community } \\
\text { Clinic }\end{array}$ & $\begin{array}{c}\text { AEGD/GPR } \\
\text { Program }\end{array}$ & $\begin{array}{c}\text { Higher } \\
\text { Education }\end{array}$ & $\begin{array}{c}\text { Other } \\
\text { Clinic Type }\end{array}$ & $\begin{array}{c}\text { Percent of Graduates } \\
\text { Choosing Community Clinics }\end{array}$ \\
\hline $1998-2000$ & 0 & $*$ & $*$ & $*$ & $*$ & $1.7 \%$ \\
2005 & 3 & 6 & 29 & 18 & 39 & $6.1 \%$ \\
2006 & 3 & 6 & 24 & 23 & 42 & $5.1 \%$ \\
2007 & 4 & 6 & 20 & 17 & 55 & $5.7 \%$ \\
2008 & 5 & 7 & 30 & 23 & 44 & $11.8 \%$ \\
2009 & 8 & 13 & 35 & 20 & 38 & $16 \%$ \\
2010 & 8 & 18 & 28 & 11 & 46 &
\end{tabular}

*The records for the 1998-2000 data are no longer available, but the percentages were calculated for a published abstract about the program. See Piskorowski WA, Fitzgerald M, Stefanac SJ. Influence of community outreach experiences on student intent to treat underserved populations (Abstract 134). J Dent Educ 2008;72(2):239-40. 
patients as more than 50 percent of their practice. It is important to note that asking questions about perceived ability before the rotations when students had already completed them introduces a potential bias. The better approach would have been to survey the students both before and after their rotations for the most accurate measure of change.

Our data demonstrate that the number of students who chose a community dental clinic as their first career path increased as the time spent in rotations increased. This increase was most dramatic when students participated in eight weeks of CBDE rotations that included multiple clinic types. Before the CBDE rotations (from 1998 to 2000), only 1.7 percent of students chose to practice in a community dental clinic, but when students spent at least three weeks in CBDE rotations the percentage increased to 6.1 percent. This suggests that any participation in CBDE, even for a few weeks, can increase students' selection of community dental clinics as their first career path. Finally, when the outreach rotations increased to eight weeks and included multiple clinic types, 11.8 percent of students in 2009 and 16.5 percent in 2010 chose to practice in a community dental clinic. These findings suggest that more weeks in CBDE rotations that include multiple clinic types may increase the number of students who choose community-based clinics as their first career choice. It is important to note that the students who entered a postdoctoral general dentistry program after graduation may also choose to work in a community-based clinic after completing the program, which would increase the percentage of graduates ultimately working in community clinics. A long-term study would produce a more accurate representation of these graduates' practice locations.

The goal of the community-based dental education program at the University of Michigan School of Dentistry is to enhance students' educational and clinical experiences as well as promote dental health equity for all populations. The program experience supports patient-centered care that teaches students an ethic of care and civic responsibility. By offering the experience of working with patients at or below 200 percent of the U.S. poverty level with complex medical problems in a variety of health care delivery systems, students become confident in their didactic and clinical skills in treating low-income and underserved populations. When students are given this kind of exposure to the needs and challenges of caring for the underserved, they become prepared to work with these populations in their future practice. However, our endeavors never remain static, and we always try to remember two important points. First, since oral health care is a dynamic profession, nothing remains "as is" for very long. We have to be nimble. Therefore, we try to do our best to adapt to the needs of our partners who are doing their best to respond to the needs of patients in their communities. Our flexibility conveys an important message to our students: that they too will have to be adaptable as practitioners. Second, the number of school-approved community sites is always changing and growing because we are constantly searching for the most effective model. It is important to observe approaches taken by our partners in communities across the state and even at different clinics within the same community. Learning that one size does not fit all helps students become more familiar with the diverse opportunities in dentistry. It is our hope that, through these influential experiences, our young professionals will take an active role in our profession that will ensure that all have access to care.

\section{Conclusions}

Community-based dental education improves students' skills and confidence level in treating underserved patients. This study suggests that increased time spent in CBDE rotations, specifically more than five weeks in multiple clinic types, may influence the likelihood that students will select community dental career paths as their first career choice. Identification of the underlying motivations behind these career choices requires further investigation.

\section{REFERENCES}

1. Bailit HL. Financial impact of community-based dental education. J Dent Educ 2010;74(10 Suppl):S33-41.

2. Andersen RM, Carreon DC, Friedman JA, Baumeister SE, Afifi AA, Nakazono TT, Davidson PL. What enhances underrepresented minority recruitment to dental schools? J Dent Educ 2007;71(8):994-1008.

3. Hryhorczuk C, Bolden AJ, Knight GW, Punwani I, Mulvihill DM, Noorullah K, Evans CA. A model for selection and assessment of community-based sites for dental students' extramural clinical experiences. J Dent Educ 2008;72(2):153-71.

4. Strauss RP, Stein MB, Edwards J, Nies KC. The impact of community-based dental education on students. J Dent Educ 2010;74(10 Suppl):S42-55.

5. Smith M, Lennon MA, Brook AH, Robinson PG. A randomized controlled trial of outreach placement's effect on dental students' clinical confidence. J Dent Educ 2006;70(5):566-70. 
6. Smith M, Lennon MA, Brook AH, Blinkhorn FA, Blinkhorn AS, Robinson PG. A randomized controlled trial of the effect of outreach placement on treatment planning by dental students. Br Dent J 2006;Suppl:27-31.

7. Bean CY, Rowland ML, Soller H, Casamassimo P, Van Sickle R, Levings K, Agunga R. Comparing fourth-year dental student productivity and experiences in a dental school with community-based clinical education. J Dent Educ 2007;71(8):1020-6.

8. Davidson PL, Carreon DC, Baumeister SE, Nakazono TT, Gutierrez JJ, Afifi A, Andersen RM. Influence of contextual environment and community-based dental education on practice plans of graduating seniors. J Dent Educ 2007;71(3):403-18.

9. Davidson PL, Nakazono TT, Carreon DC, Bai J, Afifi A. Practice plans of dental school graduating seniors: effects of the pipeline program. J Dent Educ 2009;73(2 Suppl):S283-96.

10. Butters JM, Winter PA. Professional motivation and career plan differences between African-American and Caucasian dental students: implications for improving workforce diversity. J Natl Med Assoc 2002;94(6):492-504.

11. Butters JM, Winter PA. The effects of gender and race on practice pattern preferences of dental students. J Am Coll Dent 1999;66(3):39-46.
12. Eliason BC, Guse C, Gottlieb MS. Personal values of family physicians, practice satisfaction, and service to the underserved. Arch Fam Med 2000;9:228-32.

13. Thind A, Atchison K, Andersen R. What determines positive student perceptions of extramural clinical rotations? An analysis using 2003 ADEA senior survey data. J Dent Educ 2005;69(3):355-62.

14. Atchison KA, Thind A, Nakazono TT, Wong D, Gutierrez JJ, Carreon DC, Andersen RM. Community-based clinical dental education: effects of the pipeline program. J Dent Educ 2009;73(2 Suppl):S269-82.

15. Smith CS, Ester TV, Inglehart MR. Dental education and care for underserved patients: an analysis of students' intentions and alumni behavior. J Dent Educ 2006;70(4): 398-408.

16. DeCastro JE, Matheson PB, Panagakos FS, Stewart DC, Feldman CA. Alumni perspectives on community-based and traditional curricula. J Dent Educ 2003;67(4):418-26.

17. Piskorowski WA, Fitzgerald M, Stefanac SJ. Influence of community outreach experiences on student intent to treat underserved populations (Abstract 134). J Dent Educ 2008;72(2):239-40. 